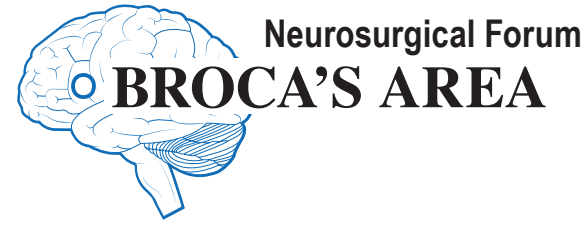

\section{Reflections on developing pediatric neurosurgery in Sub-Saharan Africa}

\section{A. Leland Albright, MD}

La Grange Park, Illinois

$\mathrm{I}$ N 2011, the World Bank estimated the population of Sub-Saharan Africa (SSA) to be $874,841,049$, with $44 \%$ of the population being 1-14 years old (http://www. tradingeconomics.com/sub-saharan-africa/populationtotal-wb-data.html). Millions of children in SSA have hydrocephalus, spina bifida, and other common pediatric neurosurgical conditions.

Kijabe, Kenya, is a village of approximately 5000 people located $65 \mathrm{~km}$ northwest of Nairobi, at an altitude of 7220 feet within the Rift Valley Escarpment. It is home to Kijabe Hospital and was founded at that site by missionaries in 1915, because its elevation was too high for malaria-bearing mosquitoes. The hospital is a 283-bed general hospital under the auspices of the Africa Inland Church. Its consultant staff consists of approximately 20 Kenyan physicians and 20 expatriate medical missionary physicians.

Dr. Dick Bransford, a career missionary general surgeon, initiated pediatric neurosurgery (PNS) in Kijabe in 1997, when he began treating children with hydrocephalus and spina bifida. The number of those children increased steadily, and in 2001, Dr. Bransford inserted 119 ventriculoperitoneal shunts and closed 61 myelomeningoceles (MMCs). In 2002, he sent an email to me with the subject "Neurosurgeon Needed," requesting help in the management of such children. I began going to Kijabe for 2-3 weeks most Januaries thereafter to teach and operate. My wife, Susan Ferson, a pediatric nurse practitioner, and I moved to Kijabe on September 1, 2010, to teach and to perform PNS. We ended our work there in January 2015. In this manuscript, I offer my reflections on developing PNS in Kenya and in SSA in general.

\section{Pediatric Neurosurgical Education in Kijabe}

There are no fellowship-trained pediatric neurosurgeons on the University of Nairobi faculty, as is true of almost all other African neurosurgery faculty. Approximately 12 neurosurgery residents from Nairobi came to Kijabe for their PNS rotations, which were structured like resident rotations in the US. Our intent was to teach them how to evaluate patients, to identify therapeutic options, to read scans, to operate, to do clinical research, and to publish manuscripts-basically, how to be neurosurgeons. Eighteen US neurosurgery residents (from 12 American residencies) and two US PNS fellows came for rotations of 2-4 weeks. Residents were usually in the postgraduate Year 5 or 6 , so that they could help with the workload as well as learn. They evaluated and helped operate on many children with disorders they would rarely see in their home institutions. For example, approximately 250 children with MMCs were operated on in 2011 and a similar number in each subsequent year, and several children with frontonasal encephaloceles were treated every year. Teaching of fellows and residents was augmented by 14 pediatric neurosurgeons who visited for 2-4 weeks from the US and Canada.

When we moved to Kijabe, my main teaching hope was to train pediatric neurosurgeons. The Medtronic Foundation provided grant support for 3 years for PNS fellowships. The first fellow was Ugandan neurosurgeon Dr. Humphrey Okechi, who had just completed his neurosurgical residency in China and who began his fellowship in November 2010. His fellowship was similar to those offered in the US, with daily rounds, evaluation of outpatients, daily operations, presentation of a paper at the International Society of Pediatric Neurosurgery meeting, and publication of manuscripts. During the year, Dr. Okechi did or assisted on some 750 cases. He was given written examinations every 4 months, based on the second edition of the textbook Principles and Practice of Pediatric Neurosurgery, ${ }^{3}$ and he authored or coauthored 7 manuscripts. After working with me for 2 years, he became a 
consultant on the Kijabe Hospital staff and my colleague. Accreditation for the fellowship was requested from the University of Nairobi-such certificates are highly valued in Africa-but was not received. Accreditation of the fellowship from the College of Surgeons of East, Central and South Africa (COSECSA) may be possible in the future.

It was a principle of mine to not offer the fellowship to applicants I had never met or to those whose visits to Kijabe indicated they would probably not become reasonably good pediatric neurosurgeons. The second fellowship was discontinued after a few months because it seemed that goal would not be met. The third fellowship was completed under the tutelage of Dr. Okechi in August 2015.

\section{Research}

It was possible to do both retrospective and prospective clinical research in Kijabe, particularly research into disorders such as MMCs that are far less common in developed countries. My wife, Susan, kept a prospective database on every patient, which provided information for multiple publications. ${ }^{1,5,8,9}$ The main impediment to clinical research was the difficulty in obtaining follow-up. Although mobile clinics staffed by nurses and therapists for patient follow-up were held at 15 sites across Kenya, many patients never returned to clinic and many of their cell phone numbers became nonfunctional.

In January 2013, we began a randomized clinical trial, comparing infection rates and shunt complications of Codman Bactiseal shunts and Chhabra shunts. The study was interrupted in June 2014 after 100 patients were enrolled. Although every patient was given a date to return for postoperative follow-up, 13 patients were lost to followup; they either came only once or never returned and their cell phone numbers were either disconnected or incorrect. It seems that such research can only be done successfully if study coordinators are hired to obtain data from homevisit follow-ups.

\section{Equipment and Supplies}

Because the mission of Kijabe Hospital is to provide good quality medical care for poor people, its budget for neurosurgical supplies and equipment was zero. If the hospital had to pay for supplies and equipment, its charges would necessarily increase to levels that poor people could not pay. Thus, nearly all our neurosurgical equipment and supplies were donated, used, from colleagues and hospitals in the US and Canada. The hallmark of used equipment is that it breaks. When breaks occurred, repairs were rarely available in Kenya and had to be done-if they were done-in the US. Our only new equipment was a Storz endoscope and monitor purchased with a grant from the Medtronic Foundation, and a Myriad tissue resector donated by the NICO Corporation. Supplies needed on a daily basis, such as Ioban, cottonoids, Dermabond, and microscope drapes, were brought every $2-3$ months by short-term visiting pediatric neurosurgeons or neurosurgery residents. Kijabe Hospital, like many if not most hospitals in SSA, had no CT scanner while we were there. A single-slice scanner was donated in 2013, but it broke after 4 months and was not repaired because of cost. (CT and MR scans are available in Nairobi, but at prices most patients cannot afford, approximately $\$ 75$ for a CT scan and \$200 for an MR image.) A CT scanner was procured within a few months after we left Kijabe.

As the work began, I sought to obtain several highertech instruments that are routinely used in the States, rather than the instruments that would be available to Kenyan neurosurgeons after their training-instruments such as a brace-and-bit, Gigli saw, and rongeurs. It took approximately 1.5 years to get an adequate, donated, used operating microscope, a functional used Midas Rex drill, and a new endoscope for endoscopic third ventriculostomies (ETVs). Whether such equipment will remain available and functioning in Kijabe in coming years is unknown.

\section{Aspects of Clinical Care in Kijabe}

It was helpful to have practiced PNS for many years before moving to Kenya. I used to tell residents in the States that even after doing PNS for many years, I continued to see a child once a month with a condition I had not seen before. In Kenya, that occurred more than once a week. Children presented for care late, partly because their families could not pay for transportation to the hospital, partly because they were taken first to the practitioners of traditional medicine, and partly because they were kept for days or weeks in hospitals that received daily reimbursements from the government for the hospitalization even though no neurosurgical treatment was given.

When we arrived in Kijabe, the average daily PNS census was 15-20 patients. During our 4 years there, the daily census increased to $25-30$ patients and on a few occasions, 40 patients. We did an average of 5 operations per day, 100 per month. Although Dr. Okechi and I each operated only 4 days a week, that level of operations, approximately 5000 in the first 4 years, turned out to be unsustainable, from both a personal standpoint and from a financial standpoint. Near the end of our service, we limited the census to 20 patients and developed guidelines about cases that would not be admitted or operated on because of poor prognoses.

Treatment decisions about many patients were difficult, particularly the treatment of hydranencephaly, which some readers would consider to be unethical. Treatment was offered primarily to improve the quality of life for the family, so that they did not have to take care of an infant with a $60-\mathrm{cm}, 10-\mathrm{lb}$ head that needed to be manually turned every few hours to prevent scalp necrosis, ulceration, infection, and draining pus. In my 32-year practice in the US, I encountered fewer than 20 cases of hydranencephaly. In the 4 years in Kijabe, we saw 54 cases. They were treated with ventriculoperitoneal shunts $(\mathrm{n}=11)$, endoscopic choroid plexus coagulation $(n=18)$, choroid plexus resections $(\mathrm{n}=15)$, and "comfort care" with medications $(n=10)$. Outcomes of the different treatments will be evaluated in the coming year, but decisions at the time were made on an individual basis that took into account factors such as parent preference about treatment, costs, and the functional status of the endoscope, monitor, and Bugbee wire.

We admitted approximately 2 children with hydrocephalus every day. The most common cause of hydro- 
cephalus was MMC and the second was postinfectious. Bacterial meningitis is common in Kenya and is poorly treated. A child with fever, irritability, and poor feeding who is taken to the local governmental health facility is either considered to have malaria and treated with antimalarial medication-without testing for malaria-or given a 3- to 5-day course of antibiotics, usually an oral cephalosporin. Many of those children have meningitis/ ventriculitis, but lumbar punctures are rarely done. The children present 1-2 months later with increasing head size, and head ultrasounds often demonstrate multiloculated hydrocephalus (Fig. 1). Thousands of cases of hydrocephalus could be prevented if bacterial meningitis were accurately diagnosed and appropriately treated. Yet, one caveat is that when lumbar punctures are performed and a CSF sample is sent for culture, results are usually negative because specimens are handled improperly. Improper handling includes specimens being delayed in going to the laboratory and then sitting for hours in the sunlight before being inoculated onto agar plates.

We were able to determine appropriate treatment in perhaps $90 \%$ of hydrocephalus cases of any origin using ultrasound images, but individuals with complex multiloculated hydrocephalus were usually evaluated further with a CT scan in Nairobi. Most children with hydrocephalus who were less than 6 months old, particularly those younger than 3 months, were treated with a ventriculoperitoneal shunt, usually a Surgiwear Chhabra shunt donated by the International Federation for Spina Bifida and Hydrocephalus. Some 5\%-10\% of those shunts drained less CSF than desired, and approximately $3 \%$ of them were associated with perforation of the gastrointestinal tract or abdominal wall. ${ }^{9}$ Postoperative shunt complications occurred in $20 \%-25 \%$ of cases, including infections in approximately $15 \%$. Complications were related to a multitude of factors, including severe malnutrition, suboptimal sterilization of linen and equipment, suboptimal sterile technique, and suboptimal wound care.

We performed ETVs and choroid plexus coagulations in many children older than 6 months if the equipment was working. Storz Oi telescopes used for ETVs rarely worked for longer than 3-4 months because their glass rod

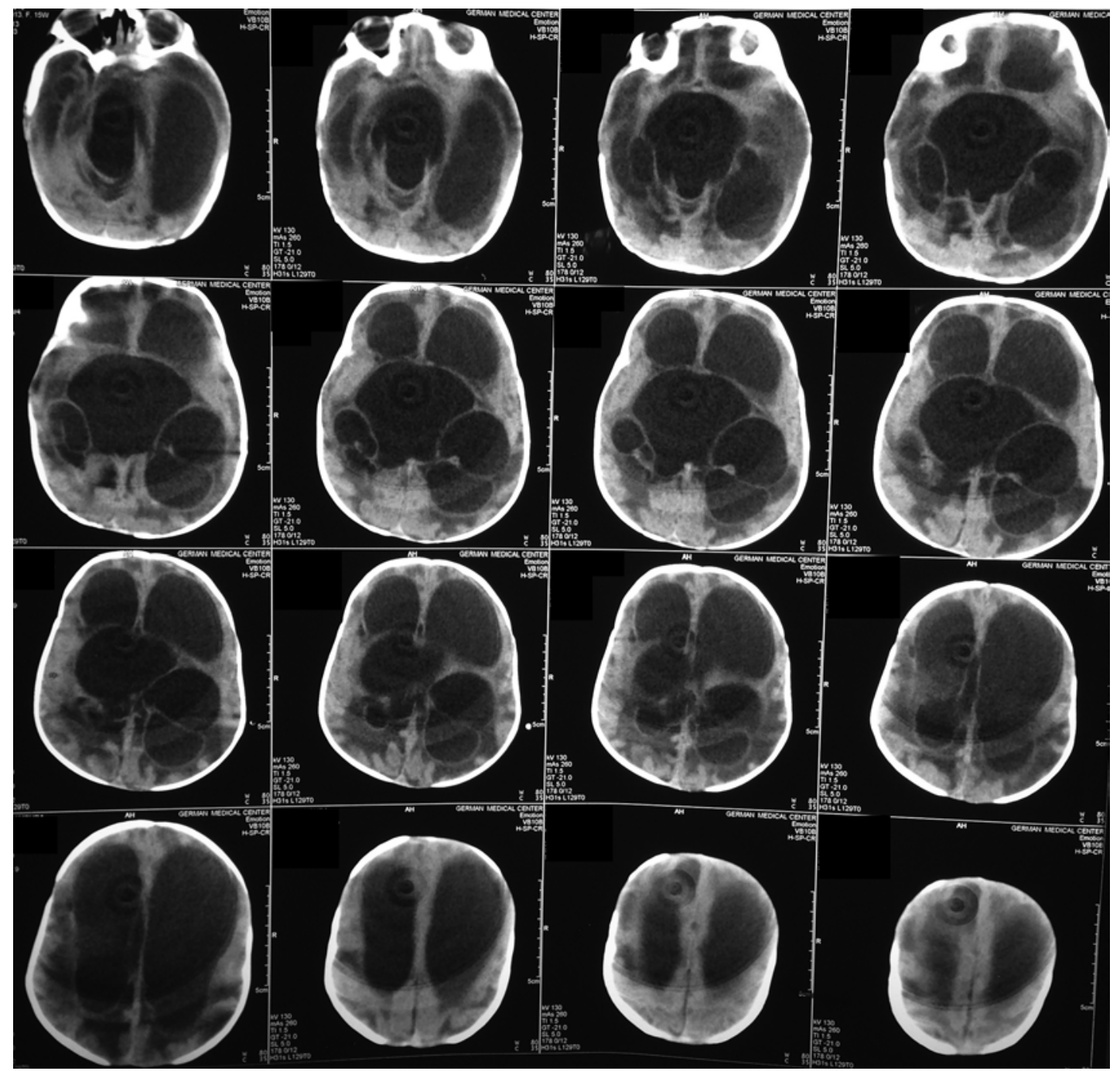

FIG. 1. Scans showing multicystic postinfectious hydrocephalus. 
lens broke from improper care and use. Decisions about whether to treat children with severe macrocephaly $(>60$ $\mathrm{cm}$ ) were made on an individual basis and took into consideration factors such as nutritional status, functional status, and socioeconomic conditions. Reduction cranioplasties on children with head circumferences $>70 \mathrm{~cm}$ were done rarely, and only if some cognitive ability was present.

An average of 5 children with unrepaired MMCs were admitted every week. Most were admitted within the first 2 months of life, but some were more than 1 year old (Fig. 2 ). Their general and neurological conditions were evaluated in an outpatient clinic and their ventricular CSF was analyzed if their anterior fontanels were patent. The care of children with grossly infected CSF (white blood cell counts $>1000 \mathrm{~mm}^{3}$ ) and the care of children with multiple malformations-e.g., thoracic MMC with chest wall deformities - was considered to be futile, and these children were sent home to receive comfort care. Most children with MMCs underwent distal cordectomies, removing the neural placode. ${ }^{2}$ Fifteen percent of infants with MMCs had a concomitant kyphotic deformity (Fig. 3), which was often treated by a kyphectomy after the placode was removed. The outcome of infant kyphectomies is unknown and is being evaluated.

Management decisions concerning children with brain tumors were likewise difficult. If a child presented with a posterior fossa tumor and a CT scan indicative of a medulloblastoma, preoperative spine MRI was never feasible (because of cost) to see if drop metastases were present. If the child was younger than 3 years (poor-risk medulloblastoma), if the family lived far from Nairobi (the only site for radiotherapy in Kenya), or if the family was too poor to pay for adjuvant therapy, we had no good therapeutic choices. On rare occasions, Susan and I personally paid for adjuvant therapy for children with better prognoses.

Craniopharyngiomas also presented treatment dilemmas. They were more common in Kenya (6-8 cases/year) than in the US, and were often large (Fig. 4). Craniotomies for complete tumor removals were almost never feasible because families were unable to afford the multiple hormone replacements that are needed postoperatively. Many craniopharyngiomas were cystic. Monocystic tumors were treated with intracyst instillations of bleomycin, and multicystic tumors with endoscopic cyst fenestrations. Chil- dren with mixed cystic-solid tumors who were younger than 8 years underwent subtotal resections to "buy time" until they were old enough to receive radiotherapy.

The issue of costs affected the clinical care of virtually every patient. Costs had to be considered when we were deciding which laboratory tests to order and which antibiotics to recommend, but costs did not alter decisions about whether to admit a child for care or about whether to operate, if an operation was indicated. Costs of hospitalizations were paid partially by the National Health Insurance Fund (NHIF) if the parents had subscribed to it (approximately \$3/month). NHIF paid approximately \$26/ day. Children with hydrocephalus were often hospitalized for 3 days and their hospital bill was roughly $\$ 500$, more than many families' annual income. In addition to the portion paid by NHIF, a small proportion of the bill was paid by the parents (sometimes with funds obtained by selling a family animal) or by extended family members, but the majority (approximately 85\%) of the bills were paid by BethanyKids (BethanyKids.org), a Christian charitable organization. As the neurosurgical caseload increased, BethanyKids was not financially able to continuously support 100 PNS cases a month in addition to supporting pediatric surgery cases, nor were Dr. Okechi and I physically able to continually do 100 cases a month. The admission and treatment guidelines were therefore developed.

\section{Perspectives on PNS in Sub-Saharan Africa}

In the second anniversary message of the Walter Dandy Society (wedns.org), president Saleem Abdulrauf estimated that there would be 183,917 new cases of hydrocephalus in SSA in 2013 and advocated for a 10-year goal of the Society that no child with hydrocephalus in SSA would be untreated by 2024 . That goal is not attainable from either a personnel or an economic standpoint.

There are fewer than 15 fellowship-trained pediatric neurosurgeons in Africa, and there are at least 5 major reasons for that dearth. 1) There are almost no academic pediatric neurosurgeons on African neurosurgery faculties who can offer fellowships. 2) To become a pediatric neurosurgeon requires an additional year of training. 3) Funding for a fellowship year is rarely available. 4) Pediatric neurosurgery pays less than adult neurosurgery. 5) Neurosurgeons prefer-as is true of doctors in general-
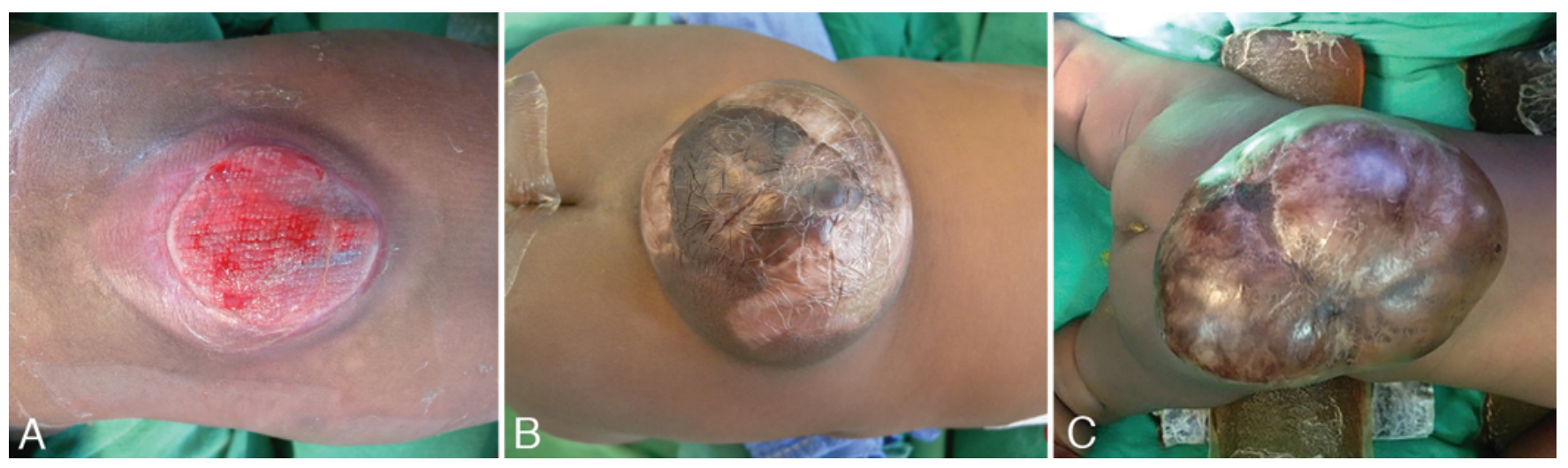

FIG. 2. Myelomeningoceles 2 days (A), 2 months (B), and 2 years (C) after birth. Figure is available in color online only. 

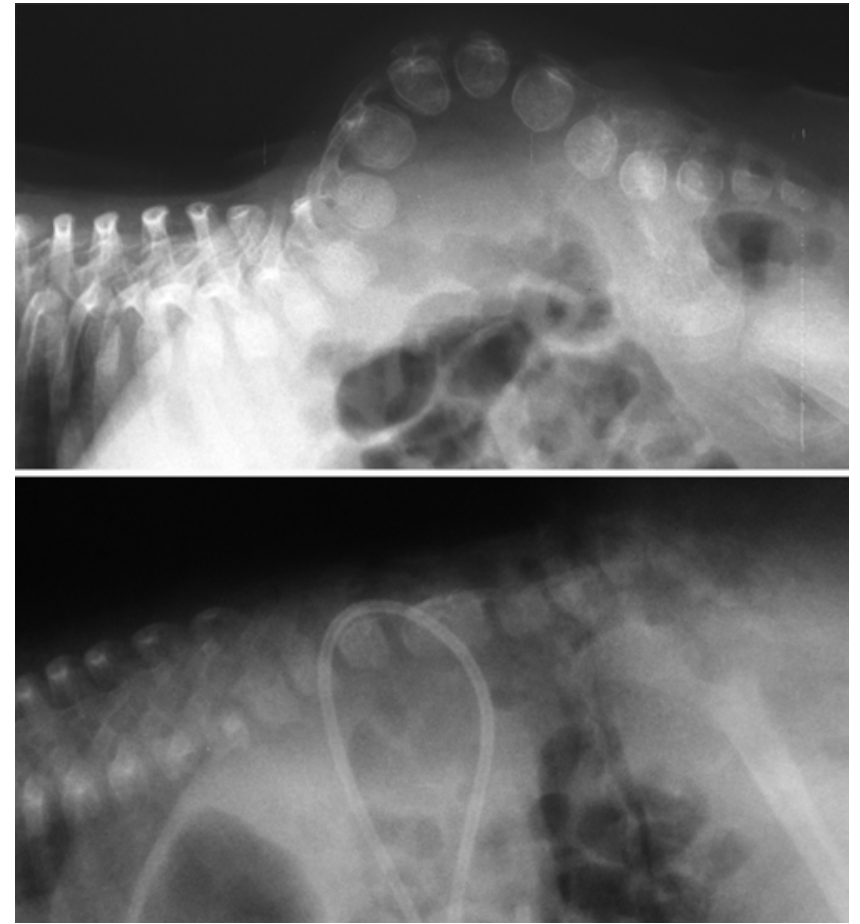

FIG. 3. Upper: Lumbar kyphotic deformity associated with a myelomeningocele. Lower: Postoperative radiograph of a patient 6 months after a kyphectomy, demonstrating fusion of adjacent vertebrae.

not to treat disabled people, and many children with pediatric neurosurgical disorders are disabled by hydrocephalus or spina bifida and die within a few years.

Because of the large numbers of infants with hydrocephalus and MMCs in SSA, Park ${ }^{6}$ has recommended that general surgeons be trained to treat hydrocephalus with shunts and to close MMCs, but there are several drawbacks to that option. 1) Academic neurosurgery training programs have little interest in training general surgeons or in treating complications of their neurosurgical operations. 2) There is minimal evidence that African surgeons seriously want such training. 3) It would take a minimum of 6 months to learn how to treat hydrocephalus well, primarily because there is far more to treating hydrocephalus than inserting shunts. Evaluating whether a shunt is functioning appropriately can be difficult, and treating shunt complications is even more complex, not something that can be learned in a 2- to 3-month tutorial. The appropriate management of shunts that have perforated the gastrointestinal tract or the abdominal wall is rarely taught to surgeons desiring to treat hydrocephalus with shunts. 4) Some hydrocephalus cases require the ability to interpret CT scans, scans that most general surgeons would not know how to interpret, and about which even pediatric neurosurgeons sometimes debate the best therapeutic option.

General surgeons, particularly missionary general surgeons in remote areas, sometimes see children with hydrocephalus and have a compassionate desire to treat these children with shunts. Such operations might be improved if free, online text and video tutorials became available. A tutorial video of the MMC repair developed in Kijabe will

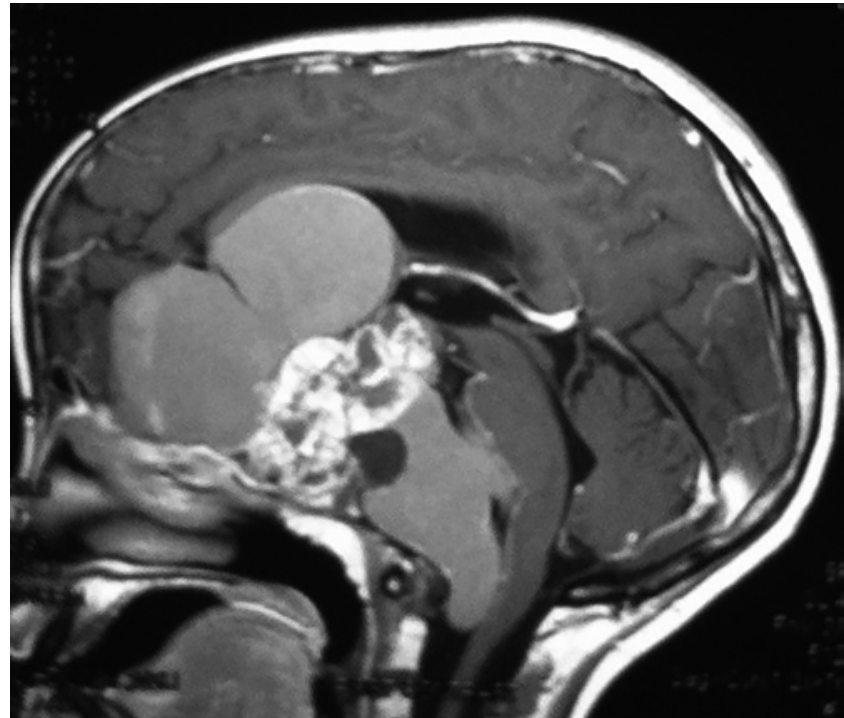

FIG. 4. Image showing multicystic mixed cystic and solid craniopharyngioma.

be available in the online Masters of Neurosurgery project in the coming months.

"Solutions" to the problems of hydrocephalus and spina bifida in SSA will never come from increased neurosurgical manpower. The high frequency of spina bifida is related to at least 4 factors that would take generations to change: 1) high birth rates (women in all Kenyan counties outside of Nairobi have an average of more than 3 children each); 2) absence of folic acid at conception (the Kenyan government legislated 2 years ago that flour/maize be fortified with vitamins and folic acid, but few Kenyan families can afford to buy fortified flour); 3) ingestion of fumonisin (most Kenyans grow their own maize and have it ground by the local miller; the flour is often stored in humid conditions and becomes infected with fungi that produce fumonisin, a mycotoxin that inhibits fetal DNA metabolism); and 4) absence of prenatal screening and abortion (abortions are illegal in Kenya and that legality is unlikely to change). Each of these factors would be difficult to change individually, and, in the aggregate, probably impossible.

The treatment of children with severe hydrocephalus and/or MMCs in SSA countries presents a social and ethical dilemma and raises the question, "Is it appropriate to try to develop pediatric neurosurgery throughout Sub-Saharan Africa?" Three factors to consider are the following: 1) Medical budgets in Sub-Saharan countries are meager, and funds are needed for the vastly greater number of people with malaria, AIDS, and tuberculosis. There are insufficient funds within those budgets to treat the thousands of children newly diagnosed with hydrocephalus in Eastern and Sub-Saharan Africa each year. Warf et al. evaluated the costs and benefits of neurosurgical intervention for infant hydrocephalus in SSA. ${ }^{10,11}$ Their treatment in 215 of 297 patients was ETV, with or without choroid plexus coagulation. They concluded that neurosurgical intervention has a cost-averted disability-adjusted life-years ratio comparable to other surgical interventions 
and a favorable benefit-cost ratio. However, it is unlikely that any SSA country would pay the millions of dollars needed to treat these children, many of whom will die within 5 years. Although $50 \%-60 \%$ of the children were successfully treated in Mbale, Uganda, a center with considerable expertise, the likelihood is low that children with postinfectious hydrocephalus or hydrocephalus secondary to spina bifida could be treated with comparable results elsewhere. Although Piquer et al. recently reported a 51\% success rate treating hydrocephalus with ETVs (without choroid plexus coagulations) and mobile endoscopic treatment in several SSA countries, 6-month follow-up was available in only $22 \%$ of cases. ${ }^{7}$ 2) Pediatric neurosurgery relies on high-tech equipment such as CT scanners and operating microscopes and endoscopes, equipment that is expensive to purchase and difficult to maintain. Head ultrasound units are more widely available but the images can be difficult to interpret. 3) Neurosurgical patients are often disabled, and many, if not most, societies in SubSaharan countries do not value disabled people. Thus, it is probably not appropriate economically or socially for countries in SSA to have a goal of treating the thousands of children with the two most common PNS disorders, hydrocephalus and spina bifida. Indeed, we would not have been able to treat the few thousand children with those disorders at Kijabe Hospital in the past 4 years without the support of BethanyKids.org.

It seems reasonable for academic neurosurgical centers in SSA countries to have a pediatric neurosurgeon on their faculty to teach residents how to treat children with hydrocephalus and MMC, but more importantly, how to treat the multitude of other common PNS disorders that occur less frequently but whose outcomes are better-disorders such as tethered spinal cords, frontonasal encephaloceles, spasticity, some brain tumors, and some brain abscesses.

\section{Sustainability}

Lastly, one of the hallmarks of PNS, and one of its features that so many pediatric neurosurgeons value highly, is the opportunity to care for children from infancy into adulthood. Unless PNS is done well, children in SSA with hydrocephalus may be treated with a shunt but then lost to follow-up and die of shunt complications. Children with spina bifida may have their MMCs repaired but then die of renal failure because they do not receive chronic care for neurogenic bladders. As Ibrahim and Bernstein write, "It may be ethically dubious - and indeed a disservice to patients - to facilitate the provision of neurosurgery without augmenting the capacity to care for patients following it." PNS done in academic medical centers or in mission hospitals with continual pediatric neurosurgical coverage seems most likely to provide the sustained care, often multidisciplinary care, the children with these disorders need. Is it ethical to offer them less?

\section{References}

1. Albright AL, Ferson SS, Okechi H: Cerebrospinal fluid white blood cell counts in infants with myelomeningoceles. J Neurosurg Pediatr 13:189-191, 2014

2. Albright AL, Okechi H: Distal cordectomies as treatment for lumbosacral myelomeningoceles. J Neurosurg Pediatr 13:192-195, 2014
3. Albright AL, Pollock IF, Adelson PD: Principles and Practice of Pediatric Neurosurgery, ed 2. New York: Thieme, 2008

4. Ibrahim GM, Bernstein M: Models of neurosurgery international aid and their potential ethical pitfalls. Am Med Assoc J Ethics 17:49-55, 2015

5. Ochieng' N, Okechi H, Ferson S, Albright AL: Bacteria causing ventriculoperitoneal shunt infections in a Kenyan population. J Neurosurg Pediatr 15:150-155, 2015

6. Park BE: The African experience: a proposal to address the lack of access to neurosurgery in rural sub-Saharan Africa. World Neurosurg 73:276-279, 2010

7. Piquer J, Qureshi MM, Young PH, Dempsey RJ: Neurosurgery education and development program to treat hydrocephalus and to develop neurosurgery in Africa using mobile neuroendoscopic training. J Neurosurg Pediatr 15:552-559, 2015

8. Shitsama S, Wittayanakorn N, Okechi H, Albright AL: Choroid plexus coagulation in infants with extreme hydrocephalus or hydranencephaly. J Neurosurg Pediatr 14:55-57, 2014

9. Thiong'o GM, Luzzio C, Albright AL: Ventriculoperitoneal shunt perforations of the gastrointestinal tract. J Neurosurg Pediatr 16:36-41, 2015

10. Warf BC: Pediatric hydrocephalus in East Africa: prevalence, causes, treatments, and strategies for the future. World Neurosurg 73:296-300, 2010

11. Warf BC, Alkire BC, Bhai S, Hughes C, Schiff SJ, Vincent JR, et al: Costs and benefits of neurosurgical intervention for infant hydrocephalus in sub-Saharan Africa. J Neurosurg Pediatr 8:509-521, 2011

\section{Disclosures}

The author reports no conflict of interest.

\section{Response. Spina bifida and hydrocephalus: Africa, attitudes, and assumptions}

\section{Benjamin C. Warf, MD}

Department of Neurosurgery, Boston Children's Hospital and Harvard Medical School, Boston, Massachusetts

In this edition of the Journal of Neurosurgery: Pediatrics, Dr. Leland Albright provides a thoughtful retrospective of the years he committed to developing PNS in Kenya. A number of topics are covered, including the challenges he faced managing children with brain tumors, which bear similarities to our own experience in Uganda. ${ }^{13}$ However, he necessarily focuses on the problems of infant hydrocephalus and spina bifida in SSA because of the arresting volume of patients and the enormity of the situation. His frustration, both with the barriers involved in making a difference for these children and the good-willed naiveté of those who would offer simplistic solutions, is shared by others of us who have invested considerable time and thought in the subject. He concludes that "solutions will never come from increased neurosurgical manpower." But, the unstated corollary must not be missed: solutions will never come without it. Complex problems often demand multifaceted solutions. What happens in the operating room is, of course, essential-without competent initial operative treatment the situation is all but hopeless for these children. But, as is the case for children with these conditions anywhere in the world, what follows the operation is also critical to their outcome. I would argue that 
progress in saving and improving the lives of these children has been discouraged by a number of widely held attitudes and a priori assumptions, and I would like to briefly address some of these here.

\section{Is Treating Hydrocephalus and Spina Bifida Cost-Prohibitive for African Countries?}

There may be as many as 200,000 new cases of pediatric hydrocephalus in SSA per year, ${ }^{4}$ and one would expect around 37,000 new MMC cases per year (conservatively based on an incidence of 1:1000 births in developed countries, a population of 961,500,000, and a crude birth rate of 38:1000 population for SSA; http://wdi.worldbank. org/table/2.1). The allocation of limited health care funds seems an obvious barrier to treating these children. But, the same is true for other common conditions. For example, the cost for HIV treatment in some SSA countries may approach three times the Gross Domestic Product, and external funding may approach two-thirds of spending on HIV services in SSA. ${ }^{1}$ In regard to malaria, a 2013 study found the combined annual cost of treatment in Tanzania and Kenya was more than $\$ 140,000,000 .{ }^{12}$ Based upon our prior economic analysis of infant hydrocephalus treatment in SSA, ${ }^{19}$ while assuming a maximum of 200,000 new cases of infant hydrocephalus in SSA per year and allowing for only a $50 \%$ success rate for combined ETV and choroid plexus cauterization $(\mathrm{CPC})^{16}$ when it is used as primary treatment (while including the anticipated cost of 2 additional shunt revision operations for children requiring shunt placement), the total lifetime cost of treatment for all hydrocephalus infants born in SSA in 1 year would be $\$ 268,500,000$, less than twice the annual cost of treating malaria in Tanzania and Kenya alone. When assessing averted disability-adjusted life-years (DALYs), our initial (\$37-\$80/DALY) and estimated lifetime (\$59-\$126/ DALY) cost of treatment for hydrocephalus in Uganda compared very favorably with other interventions that have been studied (e.g., \$172/DALY averted for trauma surgery in Nigeria). ${ }^{19}$ The same study estimated the benefit to cost ratio of hydrocephalus treatment in SSA to be from 7:1 to 50:1. Treating infant hydrocephalus in SSA is, in fact, comparatively cost-effective. What gets funded is a matter of priority and the prevailing political and societal will.

\section{Is Treating Spina Bifida and Hydrocephalus Futile in African Countries?}

If the cost of initial treatment (e.g., closing an MMC or treating hydrocephalus) is not prohibitive, then this question becomes even more important. There is often the perception that, despite initial treatment, most of these children in Africa will die anyway from the consequences of their condition (e.g., renal failure in those with MMC) or its treatment (e.g., shunt malfunction). However, we have reported evidence to the contrary. For instance, infants treated for MMC at CURE Children's Hospital of Uganda (cure.org/Uganda) had a 53\% 5-year survival rate (57\% excluding operative mortalities), but, notably, the majority of known causes of death were secondary to unrelated, preventable conditions (e.g., malaria). ${ }^{24}$ Most importantly, the only independent variable significantly related to survival was whether the child had access to a community-based rehabilitation program. Those children had 5-year survivals similar to their unaffected peers in Uganda, while the mortality rate was more than double for the others. We surmised the difference to be from a discrepancy in access to basic health care, making this a human rights issue. That study cohort has now been followed to 10 years (with 98\% follow-up). Our as-yet unpublished results show the great majority of deaths had already occurred within the first 5 years, and most survivors self-report a high qualityof-life score. In another study, we found the 5-year survival rate of infants treated for postinfectious hydrocephalus (PIH; the most severely affected group often presenting with significant primary brain injury) was $67.6 \%$ for those treated with a ventriculoperitoneal shunt and $72.8 \%$ for those treated by ETV/CPC. ${ }^{20}$ Of the latter, the majority (70\%-90\%) could walk, talk, feed, and dress themselves and were continent. These data suggest that treating infants with spina bifida and hydrocephalus in SSA is not necessarily a futile exercise. And, in the case of children with MMC, we have shown evidence suggesting childhood mortality may be most strongly related to discrimination against children with disabilities, rather than the consequences of the condition itself-that is, dying because of spina bifida, but not from it.

\section{Is There a Bias Against Children With Disabilities in Africa?}

That treatment for these children with disabilities may be neither cost-prohibitive nor futile begs the question as to why their care has not been a priority for African health ministries or global health bodies. Our MMC survival study suggested that, in the absence of communitybased follow-up, children with this condition did not have the same access to basic health care following successful initial treatment. ${ }^{24}$ That conclusion was subsequently supported by the World Report on Disability released by the World Health Organization and The World Bank in 2011. ${ }^{26}$ This study documented that people with disabilities worldwide had less access to health services, education, and employment and had worse health and socioeconomic outcomes. There has been broad international agreement that disability is a human rights issue, as reflected in the Convention on the Rights of the Child and the Convention on the Rights of Persons with Disabilities. Yet, even in the United States, disparities in access to services for those with disabilities, including health care, are reported even now more than a quarter century after passage of the Americans with Disabilities Act. ${ }^{8}$ As well, a prenatal diagnosis can lead to discrimination against children with spina bifida or hydrocephalus as a class of individuals. Many in the disability rights movement view the selective termination of infants based upon their predicted disability as counter to their principles, while some people living with spina bifida or hydrocephalus view it as an existential threat. Indeed, one might expect health care providers to experience an internal dissonance in caring and advocating for these children if they are regarded as individuals who should never have been born. The bias against children with disabilities is not confined to Africa, and one hopes that all societies will one day see past the blinders of "able-ism" in addition to racism, sexism, and other 
forms of discrimination. History teaches us to beware of any qualifiers beyond being human in the assignment of basic human rights.

\section{Can the Results Reported From CURE Uganda for Endoscopic Treatment of Hydrocephalus be Replicated in Other African Countries?}

It is logical to assume that long-term shunt dependence for a child in rural SSA would ultimately limit life expectancy, and the ability to avoid shunt dependence by endoscopic treatment can be reasonably advocated on this basis. Although our studies showed no significant difference in 5-year survival between ETV/CPC and shunt placement, any difference in survival may well have been obscured by the high childhood mortality rate due to unrelated causes. ${ }^{20,24}$ At CURE Uganda we reported success (survival with no further hydrocephalus-related operations) for ETV/CPC in $66 \%$ of infants under 1 year of age across all hydrocephalus etiologies, with $76 \%$ and $70 \%$ success rates for those with MMC and other noninfectious etiologies, respectively. ${ }^{14}$ Separate studies have subsequently shown ETV/CPC to be effective for infants under 1 year of age with more specific etiologies of hydrocephalus, including aqueductal stenosis (82\%), ${ }^{23}$ encephalocele (79\%), ${ }^{22}$ Dandy-Walker complex (69\%), ${ }^{21}$ congenital idiopathic communicating hydrocephalus (65\%), ${ }^{15}$ and PIH (63\%). ${ }^{20}$ If similar results could be replicated by neurosurgeons at other sites in SSA, this could dramatically reduce the overall burden of shunt dependence in those regions and thus eliminate the lifetime concern for death due to shunt malfunction in most children. It has thus been very encouraging to see the first evidence of this in recent publications from centers in Nigeria ${ }^{2}$ and Zambia, ${ }^{7}$ both of which are sites that were trained and equipped by our CURE Hydrocephalus program (cure.org/hydrocephalus). Both centers reported an overall success rate for ETV/CPC of around $75 \%$. Thus, countering natural concerns to the contrary, the results from CURE Uganda appear to be replicable by neurosurgeons in other SSA countries. The fact that the ratio of neurosurgeons to population in SSA is probably only around $1: 10,000,000^{25}$ gives urgency to the issue Dr. Albright raises as to whether general surgeons should be trained to treat hydrocephalus. This is a challenging and controversial topic with which we have struggled at CURE Hydrocephalus and about which I have recently commented elsewhere. ${ }^{18}$

\section{Can Progress be Made in Preventing Spina Bifida and Hydrocephalus in SSA?}

Interestingly, the two most common single causes of hydrocephalus in East Africa appear to be largely preventable. Infection and MMC combined accounted for more than $70 \%$ of infant hydrocephalus cases both in Dr. Albright's series in Kenya and in ours at CURE Uganda., 3.14 We know what needs to be done in regard to preventing the majority of neural tube defects: folic acid supplementation and fortification. This is a logistical and political challenge, but progress is slowly being made. ${ }^{27}$ Obstacles such as lack of political will, the expense, and the need to fortify locally milled wheat and corn still exist, but these are all solvable problems. Furthermore, the opportunity exists to potentially prevent somewhere between $30 \%$ and 50\% of all infant hydrocephalus in SSA if only $\mathrm{PIH}$ is prevented. Our preliminary unpublished results from prospectively collected data at partnering neurosurgery centers in Mali, Nigeria, Zambia, and Tanzania indicate that PIH accounts for 35\%-40\% of infant hydrocephalus cases in those countries spanning West, Central, and East Africa. In Uganda we found PIH to account for $60 \%$ of the cases we treated, with most resulting from neonatal infections ${ }^{17}$ that appeared to be associated with the rainfall cycle. ${ }^{10}$ However, despite ventriculoscopic findings of purulence and ependymal scarring, ventricular CSF samples obtained from these infants at time of hydrocephalus treatment failed to characterize the predominant pathogens. ${ }^{6}$ Neonatal sepsis is an enormous public health problem in SSA, with a birth incidence of about $6 \%$ and a case fatality rate of around $14 \% .{ }^{11}$ But, despite careful prospective studies of blood and CSF in clinically symptomatic infants, the pathogens responsible for neonatal sepsis in Uganda have failed to be identified in the majority of cases. ${ }^{5} \mathrm{~A}$ large, National Institutes of Health-funded prospective multicenter study is currently underway to identify the causal organisms of both neonatal sepsis and subsequent PIH in Uganda, which will enable the future construction of public health measures for prevention and effective early treatment of these infections. ${ }^{9}$ This work may lead to a significant decrease in the burden of PIH in the foreseeable future.

\section{Conclusions: Pressing on Toward the Goal}

The CURE Uganda experience has demonstrated the possibility for children with hydrocephalus and spina bifida to be treated cost-effectively and to enjoy life in the years ahead. Also, the training mission of CURE Hydrocephalus is beginning to bear tangible fruit. Still, children with disabilities face challenges and threats to their existence that can and must be eliminated. Discrimination, stigma, and decreased access to services and opportunities are a global reality for them. Neurosurgical treatment alone will not change this, but it is an essential part of the solution. Pediatric neurosurgeons have a singular role in learning how to do this in progressively safer, more effective, and contextually appropriate ways, as well as to transfer these skills to others. We can also choose to work with like-minded colleagues in other disciplines, as well as advocacy organizations, global health bodies, and ministries of health, to increase access to appropriate care and support prevention measures, and to work for societal, legal, and policy change. Oases of excellence in SSA can be developed in the midst of a rather daunting wilderness by fostering sites for comprehensive care, effective follow-up, and family support rather than focusing on operative procedures alone. This is neither easy nor quick, but this means we must work harder and work cooperatively. There are many advocates for these children in SSA, and there seems to presently be no shortage of African neurosurgeons who want to be trained. Organizations such as BethanyKids, CURE International, International Federation for Spina Bifida and Hydrocephalus, and the soon-to-be-launched alliance of organizations known as PUSH! (People United for Spina Bifida and Hydrocephalus) are actively pursuing these goals.

I have written this during a week in Mbale, Uganda, 
where I was sought out by a smiling young woman named Janet, who was one of the first infants with MMC I had treated here back in 2001. She is now a delightful teenager who is ambulatory with crutches and attending school. A few days later I had the privilege of visiting her school, composed of 16 local students, all of whom have spina bifida and/or hydrocephalus. The school, founded by one of our former CURE Uganda hospital employees, is completely owned, staffed, and operated by Ugandans. Janet's class of 6 students ranged in age from 10 to 14 years. All of them had been my patients, and all had been previously unable to attend public school because of stigma, shame, and lack of accommodation for their physical disabilities. They now appeared to be happy, hard-working students laboring under difficult circumstances with a dedicated teacher. I have sought not to make a case for treating these kids by way of anecdote or emotional appeal. I hope the numbers will speak for themselves. But it is both encouraging and challenging for me to be reminded that every number represents a person.

\section{References}

1. Avert: HIV and AIDS in Sub-Saharan Africa. (http://www.avert.org/hiv-aids-sub-saharan-africa. htm\#footnote49_0yu0mz7) [Accessed February 23, 2016]

2. Bankole OB, Ojo OA, Nnadi MN, Kanu OO, Olatosi JO: Early outcome of combined endoscopic third ventriculostomy and choroid plexus cauterization in childhood hydrocephalus. J Neurosurg Pediatr 15:524-528, 2015

3. Gathura E, Poenaru D, Bransford R, Albright AL: Outcomes of ventriculoperitoneal shunt insertion in Sub-Saharan Africa. J Neurosurg Pediatr 6:329-335, 2010

4. Kahle KT, Kulkarni AV, Limbrick DD, Warf BC: Hydrocephalus in children. Lancet 387:788-799, 2016

5. Kiwanuka J, Bazira J, Mwanga J, Tumusiime D, Nyesigire E, Lwanga N, et al: The microbial spectrum of neonatal sepsis in Uganda: recovery of culturable bacteria in mother-infant pairs. PLoS One 8:e72775, 2013

6. Li L, Padhi A, Ranjeva SL, Donaldson SC, Warf BC, Mugamba J, et al: Association of bacteria with hydrocephalus in Ugandan infants. J Neurosurg Pediatr 7:73-87, 2011

7. Mweshi MM, Amosun SL, Ngoma MS, Nkandu EM, Sichizya K, Chikoya L, et al: Endoscopic third ventriculostomy and choroid plexus cauterization in childhood hydrocephalus in Zambia. Med J Zambia 37:246-252, 2010

8. Peacock G, Iezzoni LI, Harkin TR: Health care for Americans with disabilities-25 years after the ADA. N Engl J Med 373:892-893, 2015

9. Schiff SJ: Control of the neonatal septisome and hydrocephalus in sub-Saharan Africa. (Abstract) (http:// grantome.com/grant/NIH/DP1-HD086071-01) [Accessed February 23, 2016]

10. Schiff SJ, Ranjeva SL, Sauer TD, Warf BC: Rainfall drives hydrocephalus in East Africa. J Neurosurg Pediatr 10:161167,2012

11. Seale AC, Blencowe H, Manu AA, Nair H, Bahl R, Qazi SA, et al: Estimates of possible severe bacterial infection in neonates in sub-Saharan Africa, south Asia, and Latin America for 2012: a systematic review and meta-analysis. Lancet Infect Dis 14:731-741, 2014

12. Sicuri E, Vieta A, Lindner L, Constenla D, Sauboin C: The economic costs of malaria in children in three sub-Saharan countries: Ghana, Tanzania and Kenya. Malar J 12:307, 2013

13. Stagno V, Mugamba J, Ssenyonga P, Kaaya BN, Warf BC: Presentation, pathology, and treatment outcome of brain tumors in 172 consecutive children at CURE Children's Hos- pital of Uganda. The predominance of the visible diagnosis and the uncertainties of epidemiology in sub-Saharan Africa. Childs Nerv Syst 30:137-146, 2014

14. Warf BC: Comparison of endoscopic third ventriculostomy alone and combined with choroid plexus cauterization in infants younger than 1 year of age: a prospective study in 550 African children. J Neurosurg 103 (6 Suppl):475-481, 2005

15. Warf BC: Congenital idiopathic hydrocephalus of infancy: the results of treatment by endoscopic third ventriculostomy with or without choroid plexus cauterization and suggestions for how it works. Childs Nerv Syst 29:935-940, 2013

16. Warf BC: Endoscopic third ventriculostomy and choroid plexus cauterization for pediatric hydrocephalus. Clin Neurosurg 54:78-82, 2007

17. Warf BC: Hydrocephalus in Uganda: the predominance of infectious origin and primary management with endoscopic third ventriculostomy. J Neurosurg 102 (1 Suppl):1-15, 2005

18. Warf BC: "Who is my neighbor?" Global neurosurgery in a non-zero-sum world. World Neurosurg 84:1547-1549, 2015

19. Warf BC, Alkire BC, Bhai S, Hughes C, Schiff SJ, Vincent $\mathrm{JR}$, et al: Costs and benefits of neurosurgical intervention for infant hydrocephalus in sub-Saharan Africa. J Neurosurg Pediatr 8:509-521, 2011

20. Warf BC, Dagi AR, Kaaya BN, Schiff SJ: Five-year survival and outcome of treatment for postinfectious hydrocephalus in Ugandan infants. J Neurosurg Pediatr 8:502-508, 2011

21. Warf BC, Dewan M, Mugamba J: Management of DandyWalker complex-associated infant hydrocephalus by combined endoscopic third ventriculostomy and choroid plexus cauterization. J Neurosurg Pediatr 8:377-383, 2011

22. Warf BC, Stagno V, Mugamba J: Encephalocele in Uganda: ethnic distinctions in lesion location, endoscopic management of hydrocephalus, and survival in 110 consecutive children. J Neurosurg Pediatr 7:88-93, 2011

23. Warf BC, Tracy S, Mugamba J: Long-term outcome for endoscopic third ventriculostomy alone or in combination with choroid plexus cauterization for congenital aqueductal stenosis in African infants. J Neurosurg Pediatr 10:108-111, 2012

24. Warf BC, Wright EJ, Kulkarni AV: Factors affecting survival of infants with myelomeningocele in southeastern Uganda. J Neurosurg Pediatr 7:127-133, 2011

25. World Health Organization: Country resources for neurological disorders. Neurology Atlas. (http://www.who. int/mental_health/neurology/neurogy_atlas_results-9-11.pdf) [Accessed February 23, 2016]

26. World Health Organization, World Bank: World Report on Disability. (http://www.who.int/disabilities/world_ report/2011/en/) [Accessed February 23, 2016]

27. Youngblood ME, Williamson R, Bell KN, Johnson Q, Kancherla V, Oakley GP Jr: 2012 Update on global prevention of folic acid-preventable spina bifida and anencephaly. Birth Defects Res A Clin Mol Teratol 97:658-663, 2013

\section{Disclosures}

The author reports no conflict of interest.

\section{Response. Neurosurgery is relevant and sustainable in Africa}

\section{Graham Fieggen, MSc, MD, FCS}

\section{Division of Neurosurgery, University of Cape Town, South Africa}

In this poignant and compelling retrospective, Dr. Albright reflects on his experience working in a mission hospital in Kenya for more than a decade. Initially this was 
for just a few weeks a year, but from 2011 until 2015, he and his wife lived and worked full-time at the hospital. Their motivation in going there was not simply to deliver care in one of the most under-serviced regions of the world, but also to contribute to research, training, and the development of PNS in SSA. There can be no doubting the impact of their expertise in managing countless patients who would not have received care, but quite clearly their goals were not fully achieved. This manuscript considers the reasons for this.

Having visited the hospital while Dr. Albright was there, I can attest to the hardships they encountered and can only express deep admiration for the work he and Susan did there. They have truly been in the trenches of health care in Africa and of course the problems described are real. Dr. Albright makes important and thought-provoking points about the challenges generally facing neurosurgical education and, specifically in our pediatric specialty, the difficulties of research when patient follow-up is inconsistent and the attendant frustrations of donated equipment and unreliable supplies. Worst of all, no budget was allocated for neurosurgery. Even what we would all consider the most basic of imaging modalities, a CT scanner, was not available during Dr. Albright's tenure there. Although some issues may have been specific to the institution, which remarkably has been in existance for a century, many are generally applicable.

This obviously had a huge impact on the clinical care they were able to deliver as detailed in the various cases cited. Perhaps the most important point, however, is the patients suffering from the disabilities he describes are not going away any time soon, so let us shift focus from the problems to possible solutions.

Of course neurosurgeons cannot solve these problems alone, but we can make a start. I agree with the Dr. Albright's sentiments concerning the futility of training medical officers to place shunts when they won't be able to respond to the numerous complications that may arise after placement. There are some who naively believe you require only partial training to work as a neurosurgeon in SSA; in fact, you need an even greater skill set than elsewhere in the world because you not only need to cope with an extraordinary range of pathology, but you also have to build a health care system. Nowhere else in the world is the neurosurgeon called on to play such an important leadership role.

In response to the author's question, "Is it appropriate to try to develop pediatric neurosurgery throughout Sub-Saharan Africa?," various organizations are already involved in educational programs in Africa and I believe this is the greatest opportunity facing organized PNS in the 21st century. Effectively every neurosurgeon in SSA is a pediatric neurosurgeon by virtue of caseload, and we need to find ways to deliver appropriate and effective education in the care of children with neurosurgical conditions. The African Pediatric Neurosurgery (AfPNS) Course, supported by the International Society for Pediatric Neurosurgery and the European Society for Pediatric Neurosurgery that Dr. Albright has been part of, is just the start of what should be a multifacted educational program driven by pediatric neurosurgeons. Fellowship training is available on African soil, but we need many more programs, and the growth of
CURE Children's Hospital of Uganda shows this can be achieved.

The real goal, however, lies in proper basic neurosurgical training in Africa. Well-established training centers in the north and the south, as well as countries like Senegal, Nigeria, and Zimbabwe, have a track record of doing this, with many others coming up fast. Our own experience in training neurosurgeons from Uganda, Zambia, and Kenya demonstrates it can be done and is truly sustainable. Dr. Albright's vision for the future is best captured in deeds not words; together with a number of generous North American colleagues, he has taken care of funding two talented young Kenyan trainees who are currently in our department, and they will make a tremendous contribution to realizing his own dreams when they return home in a few years' time.

Of course many African lives are still mired in poverty, corruption, and disease, but things are really changing and neurosurgeons can be at the forefront of this. African neurosurgeons have a new-found unity in the Continental Association of African Neurosurgical Societies and for those who want to see the modern face of neurosurgery in Africa, please join us in Cape Town in July 2016.

Dr. Albright concludes on an optimistic note and I would like to echo this and thank him for his extraordinary contributions to neurosurgery in Africa.

\section{Disclosures}

The author reports no conflict of interest.

\section{Response. Neurosurgical aid in the developing world: is it worth it?}

George M. Ibrahim, MD, PhD, and
Mark Bernstein, MD, MHSc, FRCSC

Department of Neurosurgery, University of Toronto, Ontario, Canada

The burden of surgical disease in low- and middle-income countries (LMICs) is staggering. A recent study by the Lancet Commission on Global Surgery estimates that 5 billion people worldwide lack adequate access to safe and effective surgical care. ${ }^{7}$ Indeed, while gains have been made over the last several decades in the delivery of multiple domains of health care in LMICs, the morbidity and mortality rates associated with common conditions needing surgery have grown in the world's poorest regions. ${ }^{7}$

Despite increasing recognition of the unmet need for increased surgical capacity, such initiatives are often relegated as low priorities by philanthropic and supranational organizations. Indeed, the largest concerted effort to augment health care and combat poverty in LMICs, the Millennium Development Goals, which were endorsed by all member states of the United Nations, failed to make mention of a single surgical condition. This is despite increasing evidence that surgical care constitutes a cost-effective component of primary care in LMICs and serves an important role in the development of health care systems and health promotion..$^{1-3}$

Under the umbrella of surgical conditions, neurosurgery is often afforded an even lower priority than other surgical 
conditions, such as appendicitis, hernias, fractures, and obstructed labor. The aforementioned Lancet Commission, for instance, emphasized the importance of timely essential surgery to three "Bellwether Procedures": cesarian section, laparotomy, and treatment of open fractures. ${ }^{7}$ The view that intervention in not worthwhile in neurosurgical conditions in LMICs is shared by stakeholders in both developed countries and LMICs. ${ }^{6}$

The collective ineptitude of the global community to provide adequate neurosurgical care to the world's most vulnerable populations has been mitigated by the work of pioneers such as Dr. Leland Albright. In the inaugural publication of Broca's Area, Dr. Albright describes his experience in Kijabe, Kenya, emphasizing his motivations, accomplishments, and challenges. His article should serve as an opportunity to reflect upon the role of neurosurgery in the developing world and as a call to arms to continue his selfless work in augmenting sustainable neurosurgical capacity in LMICs. His views, shaped by considerable experience, also raise important questions regarding the ethical underpinnings of neurosurgical treatments in LMICs and the context within which such as interventions should be offered.

Numerous models of international aid exist in neurosurgery, which can roughly be classified on the basis of the depth and commitment involved. ${ }^{5}$ Dr. Albright's work in SSA represented a highly committed initiative with a focus on the treatment of hydrocephalus and MMC. His exemplary efforts encompassed three broad areas: education, research, and capacity building. His educational work in Kijabe emphasized the teaching of local and international surgical trainees, and the development of innovative pedagogical platforms, for instance, to teach PNS to nonpediatric neurosurgeons. To his great credit, he promoted research in order to study disorders, such as MMCs, which are far more common in LMICs than in developed nations. Finally, he provided, in an underprivileged population, good quality care to thousands of children who would have otherwise been relegated to the margins of society with little possibility of medical attention.

There are myriad challenges inherent in the implementation of a neurosurgical program in the setting of outmatched resources. Dr. Albright poignantly captures the essence of those challenges in a way that can only be conveyed by an individual who has spent years struggling to find a balance between providing reasonable, ethical care and managing very limited, scarce resources. Obstacles from an educational perspective include the motivations and ultimate career choices of trainees; from a research perspective, the poor follow-up and the precious time spent collecting data; and from a capacity-building perspective, challenges with maintaining and troubleshooting equipment, patient selection (and patient exclusion), and the provision of postoperative care.

A significant challenge in LMICs is how to know whether the well-intentioned initiatives are beneficial or, perhaps even more importantly, paradoxically destructive and harmful. In a recent international study of key stakeholders in developed countries and LMICs, it was shown that the majority of individuals involved in international surgical partnerships cannot measure the impact of their programs. ${ }^{6}$ Importantly, Dr. Albright and his wife Susan recognized this critical aspect of working abroad and maintained prospective databases on every child treated in Kijabe. Albeit painstaking, particularly in resourceconstrained areas, where a surgeon's time is nearly always dedicated to clinical care and education, Dr. Albright must be congratulated for his insight and attempts to monitor and evaluate the impact of his work. His efforts have led to several publications, which will considerably advance future efforts to treat hydrocephalus and MMC in the developing world.

Ethical issues also affect nearly every patient encounter and each clinical decision in the low-resource setting. Dr. Albright's sincere account of challenges in ethical decisionmaking has been echoed by others in the field previously, including our own experience. ${ }^{4}$ In resource-limited environments, each clinical decision affects not only the individual patient, but also others who require access to the same resources, thus creating a constant dissonance between the ethical tenants of distributive justice and beneficence. What may constitute harm is a contextually significant judgment for each patient, which may take into consideration their disease burden, ability to receive follow-up care, and the unique psychosocial environment. Indeed, as Dr. Albright outlines, some patients with potentially treatable conditions (e.g., brain tumors in the absence of adjuvant care such as radio- and/or chemotherapy) are provided a disservice by surgical intervention, while others (such as children with hydranencephaly) may benefit from surgery to improve the provision of care to the child by the family.

Neurosurgical treatments in the developing world have stagnated relative to advances in the care of other conditions. Insights from pioneers in the field are also underrepresented in the literature but critical to the advancement of treatments for the world's most marginalized populations, and we commend the Journal of Neurosurgery: Pediatrics for publishing this thoughtful and erudite piece. Dr. Albright concludes by asking the international community to consider whether neurosurgery in the developing world is worth it. His own life work and legacy in Kenya would suggest that it is. And as the American publisher and philosopher Elbert Hubbard said, "There is no failure except in no longer trying."

\section{References}

1. Farmer PE, Kim JY: Surgery and global health: a view from beyond the OR. World J Surg 32:533-536, 2008

2. Gosselin RA, Thind A, Bellardinelli A: Cost/DALY averted in a small hospital in Sierra Leone: what is the relative contribution of different services? World J Surg 30:505-511, 2006

3. Hackenberg B, Ramos M, Campbell A, Resch S, Finlayson $\mathrm{S}$, Howaldt $\mathrm{H}$, et al: Measuring and comparing the cost-effectiveness of surgical care delivery in low-resource settings: Cleft lip and palate as a model. J Craniofac Surg 26:11211125,2015

4. Howe KL, Malomo AO, Bernstein MA: Ethical challenges in international surgical education, for visitors and hosts. World Neurosurg 80:751-758, 2013

5. Ibrahim GM, Bernstein M: Models of neurosurgery international aid and their potential ethical pitfalls. Virtual Mentor 17:49-55, 2015

6. Ibrahim GM, Cadotte DW, Bernstein M: A framework for the monitoring and evaluation of international surgical 
initiatives in low and middle income countries. PLoS One 10:e0120368, 2015

7. Meara JG, Leather AJ, Hagander L, Alkire BC, Alonso N, Ameh EA, et al: Global Surgery 2030: Evidence and solutions for achieving health, welfare, and economic development. Surgery 158:3-6, 2015

\section{Disclosures}

The authors report no conflict of interest.

\section{Reply}

\section{A. Leland Albright, MD}

La Grange Park, Illinois

I am grateful to Drs. Fieggen, Ibrahim and Bernstein, and Warf for such thoughtful commentaries. Their remarks coincidentally focused separately on the three primary aspects of the manuscript: education, research, and capacity building.

Dr. Fieggen, who has been the leader of pediatric neurosurgical education in Africa, emphasized the need for improved education in PNS for African neurosurgery residents. That education would be optimally provided by fellowship-trained pediatric neurosurgeons on African neurosurgery faculties, ideally pediatric neurosurgeons whose fellowships were in Africa. Dr. Fieggen and his colleagues offer excellent PNS fellowships, but such fellowships are available in few other places in Africa, for reasons described in my manuscript. Moroccan Professor El Khamlichi has written that "The future development of neurosurgery in Africa will depend mainly on the efforts of African neurosurgeons to improve neurosurgery in their respective countries." I I suspect his statement is as true for the development of PNS in individual countries as it is for neurosurgery as a whole.

Dr. Fieggen and his colleagues have also addressed pediatric neurosurgical education by developing the AfPNS courses that are supported by the International Society of Pediatric Neurosurgery and the European Society of Pediatric Neurosurgery. The AfPNS course I participated in, in March 2014, was attended by approximately 35 African neurosurgeons and residents, and its quality was comparable to that of PNS conferences in the US. In my perhapsbiased opinion, I believe the American Society of Pediatric Neurosurgery should also support AfPNS courses if such support were requested.

Drs. Ibrahim and Bernstein, leaders in international neurosurgical education and ethical neurosurgical care, addressed the difficulty of finding-as they so beautifully describe it-"a balance between providing reasonable, ethical care and managing very limited, scarce resources," and the difficulty of a "constant dissonance between the ethical tenets of distributive justice and beneficence." Their statement that ethical issues "affect nearly every patient encounter and each clinical decision" was true in our experience every day.

Drs. Ibrahim and Bernstein also emphasized the importance of collecting data, for both clinical research and for evaluating whether treatment outcomes are ethical. My wife, Susan Ferson, spent hours each week entering data from each PNS patient into a database. We were not able to find anyone else with the commitment to completing the database with the necessary accuracy. The data were invaluable in evaluating our practice, but the difficulty obtaining good-quality follow-up data limited their use in evaluating outcomes and ethical questions.

Dr. Warf, who has revolutionized the care of hydrocephalus and has demonstrated how the capacity to treat it can be built and taught in Sub-Saharan Uganda, emphasized that children with hydrocephalus can have costeffective outcomes when treated in centers such as the one he developed in Mbale. Cost-benefit analyses in these circumstances must include factors other than monetary costs, factors such as the costs to the already-impoverished family and community, the caregiver burdens, and the societal costs (and rejection) of disabled people.

The point of my statement that "solutions will never come from increased neurosurgical manpower" referred to the problems of hydrocephalus and spina bifida and was intended to mean that underpinning those two enormous problems are endemic, seminal, societal, and economic causes that are of far greater consequence than the paucity of neurosurgeons. Societal bias against children with disabilities reflects a belief that the conditions resulted from being "cursed," from the fact that disabled children are less likely to contribute to their societies with gainful employment, and from concern that boys with spina bifida would be less likely to father children and girls would not be wanted as brides and would bring reduced dowries. Those cultural attitudes developed over generations and will likely take generations to change.

The incidence of spina bifida could be reduced if folic acid supplementation and fortified maize were widely available, but unless governments provide those widely and at minimal or no cost, that will not happen. The problem of PIH is equally intractable because of the unavailability of appropriate medical care for babies with neonatal/infant sepsis, care that would diagnose and treat them in a timely manner. In my opinion, the likelihood that either of those problems will improve throughout SSA in the foreseeable future is small, and thus, the high frequency of hydrocephalus and spina bifida will persist.

I applaud the work of Dr. Warf and his colleagues. The results of their oasis of excellence in Mbale are remarkable and I look forward to similar results from multiple other centers. It may be that the best way to develop PNS in Africa is to develop multiple oases of excellence, both in academic centers and in mission hospitals with continual PNS coverage, such as Kijabe Hospital and the CURE hospital in Mbale. Those oases could be developed through collaboration between pediatric neurosurgical centers in the US (and other developed countries) and specific neurosurgical centers throughout Africa.

I believe "points of pediatric neurosurgical light" can be developed in SSA and in Africa as a whole to provide better care for many children, but I cannot see beyond that.

\section{References}

1. El Khamlichi A: African neurosurgery: current situation, priorities, and needs. Neurosurgery 48:1344-1347, 2001 